\title{
A disseminação da epidemia da AIDS no Brasil, no período de 1987-1996: uma análise espacial
}

\author{
The spread of the AIDS epidemic in Brazil \\ from 1987 to 1996: a spatial analysis
}

Celia Landmann Szwarcwald 1

Francisco Inácio Bastos 1

Maria Angel a Pires Esteves 1

Carla L. Tavares de Andrade 1

1 Departamento de Informações em Saúde, Centro de Informação Científica e Tecnológica, Fundação Oswaldo Cruz Av. Brasil 4365,

Rio de Janeiro, RJ

21045-900, Brasil.
Abstract Mean AIDS incidence rates were cal culated for threetime periods, 1987-89, 1990-92, and 1993-96, using reported adult AIDS cases by county. The analysis included the following variables: "population of counties for resident AIDS cases"; "proportion of population residing in urban areas", and "concentration of poverty", stratifying by gender and exposure categories. The Southeast region has experienced the lowest increase, contrasting with the steep ri se observed in the North and South between the second and third study periods. Comparing variations in incidence rates from 1990-92 and 1993-96 by regi on or population, the greatest increase was among women. In the larger cities, AIDS cases among "homo/bi sexual men" predominate, although the proportion of cases among men who have sex with men has decreased as heterosexual cases have undergone a continuous increase. IDUs have been the core stratum in medium-sized counties. For the smallest counties, heterosexual transmission has been the basic element in local dynamics. Even though AIDS is still an urban phenomenon in Brazil, the epidemic is spreading to rural counties. Until recently it has mainly affecting rel atively more affluent areas, but there is now an evident spread of the epidemic to poorer areas.

Key words Acquired Immunodeficiency Syndrome; Spatial Analysis; Ecological Studies; Epidemiology

Resumo As taxas médias de incidência da AIDS em adultos no Brasil foram estimadas para os períodos 1987-89, 1990-92 e 1993-96, segundo o município de residência dos casos. Nas análises foram utilizadas as variáveis "tamanho da população do município de residência”; "proporção de população que vive em área urbana" e "concentração de pobreza", estratificando-se por sexo e categoria de exposição. A Região Sudeste apresenta menor ritmo de crescimento em contraste com os acli ves acentuados das regiões Norte e Sul, do 20 ao 30 intervalo. Cotejando-se as variações das taxas deincidência de 1990-92 a 1993-96 por região ou tamanho de população, obtém-se maiores aumentos relativos entre as mul heres. Nas cidades grandes, a categoria "homo/bissexuais" prevalece, decrescendo proporcionalmente à medida que cresce o número de casos por transmissão heterossexual. Nos municípios médios predominam os usuários de drogas injetáveis e nos menores há aumento dos casos por transmissão heterossexual. A epidemia - ainda fenômeno urbano - dá sinais de expansão nos municí pios rurais, intensificando-se naqueles si tuados abaixo do limite crítico regional do índice de pobreza. Há dissemi nação crescente da epidemia nos municípios mais pobres. Palavras-chave Síndrome da Imunodeficiência Adquirida; Análise Espacial; Estudos Ecológicos; Epidemiologia 
Introdução

A epidemia pelo HIV/AIDS é hoje, no Brasil, um fenômeno de grande magnitude e extensão. O primeiro caso de AIDS foi notificado retrospectivamente na cidade de São Paulo, em 1980 (MS, 1999). A este caso inicial seguiramse outros, basicamente restritos às denominadas metrópoles nacionais - São Paulo e Rio de Janeiro -, tendo como categorias de exposição preponderantes os homens que faziam sexo com outros homens - homossexuais e bissexuais masculinos -, os hemofílicos e as demais pessoas que receberam sangue e hemoderivados (Bastos et al., 1995).

Em razão de os hemofílicos receberem habitual mente componentes sangüíneos de um conjunto (pool) de doadores - até então, habitualmente pagos pelas doações -, este segmento populacional foi rápida e profundamente atingido no início da epidemia no Brasil (Carvalho et al., 1987). O clamor público e a mobilização de diversas instâncias de fiscal ização regional determinaram alterações relevantes no quadro da transmissão secundária ao recebimento de sangue e hemoderivados, principalmente a partir da disponibilidade de testes laboratoriais para a detecção de anticorpos antiHIV, em 1986 (Andrada-Serpa et al., 1989). Observou-se, desde então, substancial decréscimo dos casos de AIDS pertencentes a esta categoria de exposição, ainda que com a persistência de exceções relevantes.

Em meados da década de 80, outro segmento populacional, aquele constituído pelos usuários de drogas injetáveis (UDI), passou a ocupar posição de destaque entre os casos secundários à transmissão sangüínea, perfazendo hoje cerca de $20 \%$ dos casos acumulados no País (Fonseca \& Castilho, 1997).

No âmbito da transmissão sexual, o segmento composto dos homens que fazem sexo com homens foi o mais severamente afetado no início da epidemia. Entretanto, à extensa disseminação inicial seguiu-se certa estabilização em anos posteriores à epidemia, em especial entre aqueles homens pertencentes às camadas médias urbanas, em meio aos quais verificou-se relevante mobilização social e mudança de comportamentos no sentido de práticas sexuais mais seguras (Parker, 1994).

O mesmo não se pode dizer em relação às populações de recorte menos definido e menor visibilidade, enquanto segmento populacional específico a ser objeto de estratégias de prevenção, como nos casos de pessoas infectadas pelo HIV em decorrência da transmissão heterossexual. Particularmente, a freqüência de casos entre mul heres cresceu substancial mente, assumindo papel central na presente década.

Em anos recentes, dentro desse panorama da epidemia no qual predomina a transmissão heterossexual, a AIDS vai deixando de ser uma doença de segmentos populacionais sob particular risco e vai-se disseminando, pari passu, na denominada população geral, embora com dinâmicas distintas nos diferentes segmentos populacionais. Tendo alcançado dimensão claramente nacional, a epidemia pelo HIV/AIDS não se restringe mais aos grandes centros urbanos nacionais e atinge atual mente mais da metade dos quase cinco mil municípios brasileiros, com disseminação espacial maior, nos últimos anos, entre municípios pequenos, que são os mais pobres e têm a menor renda per capita.

Neste sentido, após as profundas transformações no perfil da epidemia de AIDS no Brasil, determinadas pelos processos denominados "heterossexualização" e "feminização", as investigações mais recentes se dirigem a tentar estabelecer os grupos populacionais sob maior risco, que terão velocidades mais intensas de disseminação nos próximos anos. Em um país caracterizado por extremas desigualdades sociais, marcadas por diferenças relevantes não só nos padrões de distribuição de renda e de educação, mas também nos de acesso aos serviços e programas de saúde, são crescentes as especulações acerca da "pauperização" da AIDS.

Ainda que limitadas pela defasagem temporal relevante entre infecção pelo HIV e registro de caso de AIDS (Porter et al., 1999), as análises que adotam como base de informações os casos de AIDS notificados constituem um componente essencial de avaliação da dinâmica espaço-temporal da epidemia.

O presente estudo analisa a evolução espacial dos casos de AIDS no Brasil, diagnosticados no período de 1987 a 1996, contemplando a disseminação da epidemia segundo características dos municípios de residência dos casos.

\section{Metodologia}

Para a análise desenvolvida neste trabalho, utilizou-se o Sistema Nacional de Notificação (SINAN), da Coordenação Nacional de DST e AIDS (CNDST/AIDS) do Ministério da Saúde, como fonte de informações para os casos de AIDS. Foram considerados todos os casos notificados com 15 anos e mais de idade, com ano de diagnóstico no período de 1987 a 1996. Visando reduzir o viés introduzido nas tendências temporais pelo atraso na notificação (Barbosa \& Struchiner, 1997), o ano de 1996 foi o 
último ano a ser considerado para a presente análise.

Para o cálculo das taxas de incidência, os denominadores foram estimados a partir de interpolações geométricas das populações dos Censos Demográficos de 1980 (IBGE, 1983) e 1991 (IBGE, 1993), bem como da Contagem de População de 1996 (IBGE, 1997).

Para o acompanhamento da evolução temporal da epidemia, foram estimadas taxas médias de incidência para os períodos 1987-89, 1990-92 e 1993-96.

A análise dos casos foi realizada segundo sexo e categoria de exposição. Para esta, foram consideradas as seguintes categorias: "homo/ bissexuais"; "heterossexuais"; "usuários de drogas injetáveis" (UDI); “sangue”; e “ignorada” compostas pelo agrupamento das categorias simples correspondentes acrescidas das múltiplas, conforme o princípio de hierarquização da "Joint United Nations Programme on HIV/AIDS" - UNAIDS (1999), tal como exposto na Tabela 1.

No tocante à análise espacial, foram estabelecidos dois recortes. O primeiro, visando ao estudo da evolução temporal das taxas de incidência de acordo com a divisão tradicional das grandes regiões do País. A abordagem do segundo foi realizada a partir de características dos municípios de residência dos casos notificados. Foram definidas três variáveis: “tamanho da população do município de residência" (0-50.000 habitantes; 50.001-200.000 habitantes; 200.001-500.000 habitantes; mais de 500.000 habitantes), "proporção de população que vive em área urbana" ( $\geq 50 \%$ - predominantemente urbano; $<5 \%$ - predominantemente rural) e "concentração de pobreza", medida pela proporção de chefes de família com renda mensal inferior a um salário mínimo. Em virtude das desigualdades sócio-econômicas das regiões brasileiras, esta última variável foi categorizada em dois níveis, com limites críticos das faixas de pobreza distintos por grande região. No caso da "concentração de pobreza" do município de determinada região ultrapassar a "concentração de pobreza" mediana daquela região, o município foi classificado como "relativamente mais pobre" e, na situação inversa, como "relativamente mais rico".

A disseminação espacial da epidemia de AIDS segundo as características dos municípios foi apreciada mediante mapas temáticos construídos por meio do software Maplnfo (1994).
Tabela 1

Hierarquia de modos presumíveis de transmissão.

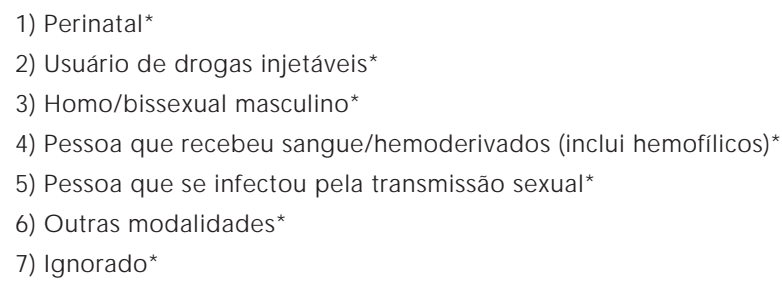

* Em caso de múltiplos riscos, os casos serão atribuídos às categorias acima listadas, seguindo a ordem hierárquica de modos presumíveis de transmissão. Fonte: UNAIDS (1999).

\section{Resultados}

Os dados expostos na Tabela 2 caracterizam a evolução temporal da epidemia no Brasil, permitindo observar a disseminação da doença por grande região e pelo tamanho da população dos municípios. Para a totalidade do País constata-se que, do primeiro para o segundo período, entre os indivíduos com 15 anos e mais de idade, a taxa de incidência cresceu aproximadamente $150 \%$, ou, expresso de outro modo, 36\% ao ano. Já de 1990-92 para 1993-96, a velocidade de crescimento diminuiu para $12 \%$ ao ano.

Observando as taxas médias de incidência segundo macro-região e período de tempo, percebe-se que as maiores taxas de incidência correspondem à Região Sudeste, que têm, entretanto, o menor ritmo de crescimento e a maior tendência à estabilidade. Chamam a atenção os aclives acentuados das regiões Norte e Sul, do segundo para o terceiro intervalo de tempo. No último período estudado, a Região Sul passou a ocupar o segundo lugar no que se refere à magnitude das taxas de incidência, ultrapassando a Centro-Oeste, que mantinha essa posição até o segundo período de tempo (Tabela 2).

Já a apreciação da expansão da epidemia de acordo com as categorias populacionais dos tamanhos dos municípios mostra que a epidemia teve início nos grandes centros urbanos, mas que são estes mesmos centros que detêm o menor aumento relativo. Vale notar que a velocidade de expansão da doença varia inversamente com a faixa populacional: tanto menor o tamanho das cidades, maior o aclive das taxas de incidência no tempo (Tabela 2).

Analisando simultaneamente as taxas médias de incidência segundo os dois recortes grande região e tamanho do município - podese apreender que, de maneira geral, os maiores 
Tabela 2

Taxas médias de incidência de AIDS (por 100 mil), segundo grande região, categoria populacional e período de tempo. Brasil, 1987-1996.

\begin{tabular}{|c|c|c|c|}
\hline \multirow[t]{2}{*}{ Categoria populacional } & \multicolumn{3}{|c|}{ Período de tempo } \\
\hline & 1987-89 & $1990-92$ & 1993-96 \\
\hline \multicolumn{4}{|l|}{ Região Norte } \\
\hline $0-50.000$ & 0,10 & 0,43 & 1,41 \\
\hline $50.001-200.000$ & 0,30 & 1,32 & 2,44 \\
\hline $200.001-500.000$ & 1,47 & 4,21 & 8,36 \\
\hline 500.001 e mais & 2,01 & 6,00 & 12,61 \\
\hline Total & 0,76 & 2,43 & 5,26 \\
\hline \multicolumn{4}{|l|}{ Região Nordeste } \\
\hline $0-50.000$ & 0,30 & 0,91 & 1,69 \\
\hline $50.001-200.000$ & 0,87 & 2,16 & 3,51 \\
\hline $200.001-500.000$ & 2,09 & 4,35 & 9,26 \\
\hline 500.001 e mais & 4,24 & 10,35 & 13,87 \\
\hline Total & 1,40 & 3,52 & 5,41 \\
\hline \multicolumn{4}{|l|}{ Região Sudeste } \\
\hline $0-50.000$ & 1,13 & 3,57 & 7,41 \\
\hline $50.001-200.000$ & 3,88 & 12,21 & 20,42 \\
\hline $200.001-500.000$ & 9,61 & 24,38 & 36,50 \\
\hline 500.001 e mais & 14,83 & 32,18 & 40,54 \\
\hline Total & 8,42 & 19,81 & 27,62 \\
\hline \multicolumn{4}{|l|}{ Região Sul } \\
\hline $0-50.000$ & 0,41 & 1,78 & 4,38 \\
\hline $50.001-200.000$ & 1,54 & 7,46 & 16,82 \\
\hline $200.001-500.000$ & 2,59 & 11,25 & 22,59 \\
\hline 500.001 e mais & 8,27 & 25,38 & 45,28 \\
\hline Total & 1,97 & 7,72 & 16,07 \\
\hline \multicolumn{4}{|l|}{ Região Centro-Oeste } \\
\hline $0-50.000$ & 0,36 & 1,40 & 3,82 \\
\hline $50.001-200.000$ & 1,15 & 5,36 & 13,04 \\
\hline $200.001-500.000$ & 4,30 & 12,06 & 20,26 \\
\hline 500.001 e mais & 4,95 & 16,48 & 24,06 \\
\hline Total & 2,37 & 8,14 & 13,97 \\
\hline \multicolumn{4}{|l|}{ Brasil } \\
\hline $0-50.000$ & 0,56 & 1,87 & 4,03 \\
\hline $50.001-200.000$ & 2,31 & 7,73 & 13,92 \\
\hline $200.001-500.000$ & 6,45 & 17,17 & 27,30 \\
\hline 500.001 e mais & 10,93 & 24,70 & 32,40 \\
\hline Total & 4,68 & 11,74 & 17,56 \\
\hline
\end{tabular}

ritmos de crescimento ocorrem entre os municípios pequenos, com menos de 50.000 habitantes, identificando-se que, nestes municípios, a epidemia está em fase inicial de expansão. Inversamente, entre as cidades grandes, com mais de 500 mil habitantes, há desaceleração da velocidade de crescimento, com exceção da Região Sul, a qual, no período 1993-96, apresentou a taxa de incidência mais elevada do País para esta categoria de municípios, superior à encontrada no Sudeste (Tabela 2).

A disseminação da epidemia de AIDS no Brasil entre os municípios pequenos em anos recentes pode ser visualizada na Figura 1 . No período $1990-92$, cerca de $20 \%$ dos municípios com menos de 50.000 habitantes haviam registrado pelo menos um caso de AIDS. Já no período 1994-96, este percentual ultrapassa 35\%. Percebe-se nítida expansão na direção noroeste, do litoral sudeste para as regiões CentroOeste e Norte.

Os dados contidos na Tabela 3 mostram as diferenças no comportamento temporal das taxas médias de incidência por sexo. Comparando-se as variações de 1990-92 para 1993-96, observa-se que os maiores aumentos relativos ocorrem sempre entre as mulheres para qualquer um dos recortes - por grande região ou por tamanho de população. Entre os homens, a epidemia nas cidades grandes da Região Sudeste já demonstra grande desaceleração do crescimento, com taxa de variação de $4 \%$ ao ano, a menor do Brasil. O mesmo não ocorre com as mulheres, cuja taxa de incidência nos municípios com mais de 500 mil habitantes, na própria Região Sudeste, tem crescimento anual de $20 \%$.

O caso da Região Sul merece consideração específica, já que mostra aumentos relevantes para ambos os sexos, em todas as categorias populacionais. Como já evidenciado anteriormente, no último período de tempo sob estudo, as taxas de incidência média entre as cidades grandes chegam a ultrapassar as apresentadas pela Região Sudeste tanto para o sexo feminino como para o masculino.

Os valores da "razão de sexos", calculada como a razão entre os casos notificados do sexo masculino e os casos do sexo feminino, estão apresentados por grande região e tamanho do município na Tabela 4. A diminuição das razões de sexos no tempo em todas as regiões mostra a notória expansão da epidemia entre as mulheres. É interessante observar que as menores razões são encontradas nos municípios com menos de 50 mil habitantes, indicando a preponderância da transmissão heterossexual nesta categoria populacional. 
1990 a 1992

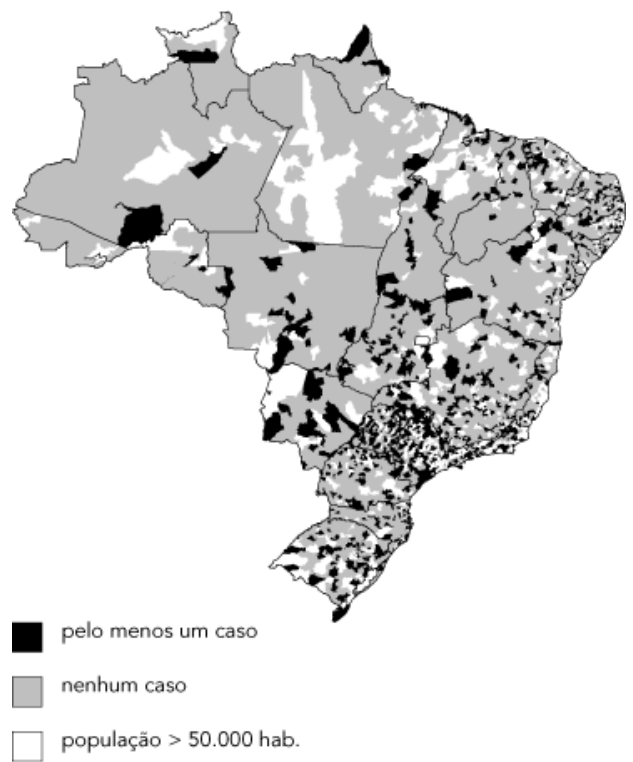

1994 a 1996

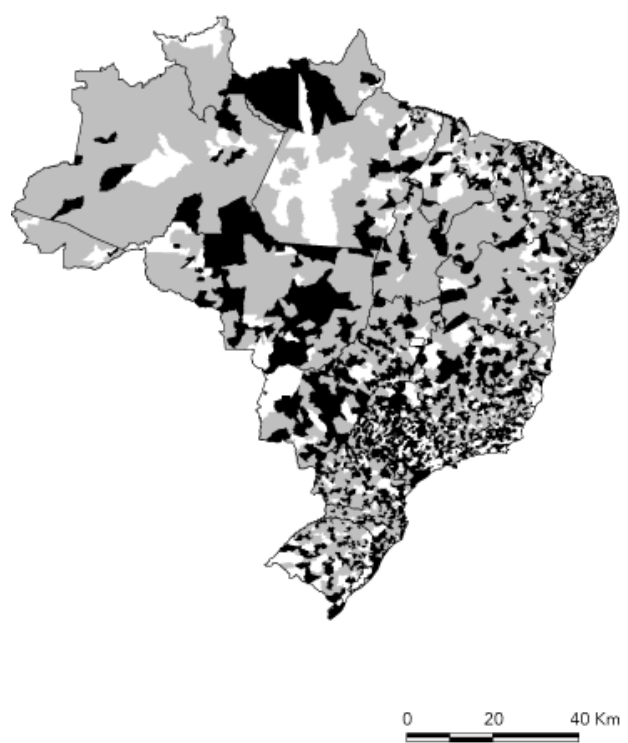

As distribuições dos casos de AIDS por categoria de exposição nas grandes regiões demonstram padrões regionais distintos (Tabela 5). As regiões Norte e Nordeste são caracterizadas pelo predomínio da transmissão sexual para ambos os sexos, com baixas proporções de casos registrados em UDI. De modo diverso, no Sul e no Sudeste, a categoria "usuários de drogas injetáveis" tem papel destacado, com percentuais semelhantes de casos heterossexuais e UDI. Vale dizer que as proporções de casos para os quais a categoria de exposição é ignorada são diferentes por região, chegando a atingir 32\% na região Centro-Oeste, o que deve ser levado em conta ao se comparar as distribuições regionais.

No que concerne à evolução temporal das distribuições dos casos por categoria de exposição, pode-se verificar que as cidades grandes têm padrão diferenciado (Tabela 6). Nestas, excluindo-se os casos com categoria de exposição ignorada, a categoria dos homo/bissexuais é a que prevalece em todos os períodos de tempo. Entretanto, esta categoria tem reduzida sua relevância ao longo do tempo proporcionalmente, à medida que cresce o número de casos por transmissão heterossexual. Nota-se ainda que os maiores percentuais de casos com categoria de exposição ignorada são encontrados nos municípios com mais de 500 mil habitantes.

Evidencia-se a preponderância da categoria dos usuários de drogas injetáveis, em todos os períodos de tempo, nos municípios de 50 a 200 mil habitantes, como também nos de porte médio - de 200 a 500 mil habitantes. Já nos municípios de menos de 50 mil habitantes, é nítido o aumento de casos por transmissão heterossexual, os quais, no último período de tempo, constituem a categoria de exposição com maior percentual de casos (Tabela 6).

Ainda analisando os dados dispostos na Tabela 6 , merecem igualmente destaque os percentuais de casos de AIDS na categoria de exposição "sangue", que, a despeito de sua substancial redução com o decorrer do tempo, ainda eram elevados no último período de tempo sob análise, em patamar superior a 3\%, nas cidades pequenas.

Os mapas apresentados na Figuras 2 e 3 mostram a disseminação da epidemia de AIDS sob outros recortes, classificando os municí- 
Tabela 3

Taxas médias de incidência de AIDS (por 100 mil), segundo grande região, categoria populacional e sexo por período de tempo e taxas de variação anual entre os dois períodos. Brasil, 1990-1996.

\begin{tabular}{|c|c|c|c|c|c|c|}
\hline \multirow{2}{*}{$\begin{array}{l}\text { Categoria } \\
\text { populacional }\end{array}$} & \multicolumn{3}{|c|}{ Sexo Masculino } & \multicolumn{3}{|c|}{ Sexo Feminino } \\
\hline & $1990-92$ & 1993-96 & $\begin{array}{l}\text { Taxa de } \\
\text { variação } \\
\text { anual (\%) }\end{array}$ & 1990-92 & 1993-96 & $\begin{array}{l}\text { Taxa de } \\
\text { variação } \\
\text { anual (\%) }\end{array}$ \\
\hline \multicolumn{7}{|l|}{ Região Norte } \\
\hline $0-50.000$ & 0,67 & 1,75 & 31,56 & 0,15 & 1,03 & 73,41 \\
\hline $50.001-200.000$ & 2,18 & 3,44 & 13,92 & 0,40 & 1,40 & 43,04 \\
\hline $200.001-500.000$ & 6,80 & 12,84 & 19,91 & 1,67 & 4,06 & 28,89 \\
\hline 500.001 e mais & 11,37 & 22,09 & 20,90 & 1,22 & 4,20 & 42,36 \\
\hline Total & 4,13 & 8,11 & 21,26 & 0,66 & 2,33 & 43,39 \\
\hline \multicolumn{7}{|l|}{ Região Nordeste } \\
\hline $0-50.000$ & 1,59 & 2,66 & 15,84 & 0,24 & 0,73 & 37,41 \\
\hline $50.001-200.000$ & 3,85 & 5,62 & 11,41 & 0,61 & 1,57 & 31,01 \\
\hline $200.001-500.000$ & 7,77 & 15,54 & 21,90 & 1,38 & 3,79 & 33,46 \\
\hline 500.001 e mais & 19,63 & 24,39 & 6,40 & 2,73 & 5,16 & 19,95 \\
\hline Total & 6,27 & 8,88 & 10,45 & 0,99 & 2,20 & 25,63 \\
\hline \multicolumn{7}{|l|}{ Região Sudeste } \\
\hline $0-50.000$ & 5,55 & 10,75 & 20,79 & 1,54 & 4,01 & 31,45 \\
\hline $50.001-200.000$ & 20,10 & 31,18 & 13,37 & 4,58 & 10,08 & 25,28 \\
\hline $200.001-500.000$ & 40,95 & 56,90 & 9,85 & 8,97 & 17,58 & 21,20 \\
\hline 500.001 e mais & 57,73 & 66,41 & 4,08 & 9,35 & 17,50 & 19,61 \\
\hline Total & 33,92 & 43,33 & 7,25 & 6,48 & 12,84 & 21,58 \\
\hline \multicolumn{7}{|l|}{ Região Sul } \\
\hline $0-50.000$ & 2,82 & 6,34 & 26,05 & 0,72 & 2,40 & 41,06 \\
\hline $50.001-200.000$ & 12,00 & 24,98 & 23,30 & 3,14 & 9,09 & 35,49 \\
\hline $200.001-500.000$ & 18,88 & 34,31 & 18,61 & 4,21 & 11,76 & 34,11 \\
\hline 500.001 e mais & 47,37 & 75,47 & 14,23 & 6,67 & 19,36 & 35,59 \\
\hline Total & 12,91 & 24,38 & 19,92 & 2,72 & 8,13 & 36,73 \\
\hline \multicolumn{7}{|l|}{ Região Centro-O este } \\
\hline $0-50.000$ & 2,07 & 5,17 & 29,89 & 0,66 & 2,35 & 43,74 \\
\hline $50.001-200.000$ & 7,43 & 18,51 & 29,80 & 3,28 & 7,58 & 27,04 \\
\hline $200.001-500.000$ & 21,29 & 31,42 & 11,76 & 3,28 & 9,68 & 36,23 \\
\hline 500.001 e mais & 29,26 & 39,28 & 8,78 & 5,15 & 10,53 & 22,67 \\
\hline Total & 13,40 & 21,14 & 13,91 & 2,09 & 6,90 & 28,10 \\
\hline \multicolumn{7}{|l|}{ Brasil } \\
\hline $0-50.000$ & 2,98 & 5,89 & 21,90 & 0,74 & 2,15 & 35,63 \\
\hline $50.001-200.000$ & 12,71 & 21,12 & 15,61 & 2,95 & 7,03 & 28,16 \\
\hline $200.001-500.000$ & 29,04 & 42,63 & 11,59 & 6,22 & 13,18 & 23,93 \\
\hline 500.001 e mais & 44,90 & 53,82 & 5,31 & 7,03 & 13,69 & 20,98 \\
\hline Total & 20,07 & 27,45 & 9,36 & 3,84 & 8,20 & 24,20 \\
\hline
\end{tabular}


pios quanto à predominância de população que vive em área rural/ urbana e quanto à concentração de pobreza. Os mapas da Figura 2 permitem dizer que a AIDS no Brasil ainda é fenômeno urbano, embora haja claros sinais de expansão também entre os municípios predominantemente rurais. Entre os municípios urbanos, a expansão pronunciada no Estado do Pará, acompanhando trechos das estradas Cuiabá-Santarém e Transamazônica, em áreas de garimpo, é digna de nota. Já em relação à concentração de pobreza, a apreciação dos mapas da Figura 3 mostra que a maior expansão ocorreu entre os municípios situados abaixo do limite crítico regional do índice de pobreza, ou seja naqueles considerados relativamente mais ricos em cada região. Porém, a disseminação de igual modo crescente entre os municípios relativamente mais pobres sugere a tendência paulatina da AIDS em atingir, de forma indiscriminada, todos os municípios do País.

A análise da expansão dos casos de AIDS entre os municípios pequenos, com menos de 50 mil habitantes, pode ser feita mediante a apreciação das informações da Tabela 7. No que se refere à urbanização, percebe-se que a disseminação da AIDS ocorreu primeiramente entre as cidades predominantemente urbanas. No que diz respeito à concentração de pobreza, os municípios relativamente mais ricos demonstraram maior expansão. Tendo em vista que o padrão obedecido não é o mesmo quando os dados são apreciados segundo a estratificação urbano/rural, compreende-se que entre os dois fatores analisados, o grau de urbanização é o que prevalece na disseminação da epidemia. Entretanto, observando especificamente a categoria dos municípios com menor expansão da epidemia, evidencia-se que, no período de 1990-92, somente 8\% destes municípios tinham pelo menos um caso de AIDS notificado, enquanto no período 1994-96 este percentual era de 19\%. Estes achados vêm corroborar as constatações anteriores de ampliação da AIDS em âmbito nacional.

\section{Discussão}

Os estudos ecológicos acerca da dinâmica da epidemia pelo HIV/AIDS são essenciais tanto ao diagnóstico das tendências da epidemia, como à proposição - e subseqüente avaliação de estratégias preventivas sensíveis às particularidades regionais e às características sócioeconômicas e culturais de diferentes segmentos populacionais, habitualmente relegadas a plano secundário nos estudos cuja base de
Tabela 4

Razão de sexos (masculino : feminino) dos casos notificados de AIDS, segundo grande região, categoria populacional e período de tempo. Brasil, 1987-1996.

\begin{tabular}{|c|c|c|c|}
\hline \multirow[t]{2}{*}{ Categoria populacional } & \multicolumn{3}{|c|}{ Período de tempo } \\
\hline & 1987-89 & 1990-92 & 1993-96 \\
\hline \multicolumn{4}{|l|}{ Região Norte } \\
\hline $0-50.000$ & $-*$ & 5,00 & 1,91 \\
\hline $50.001-200.000$ & 5,00 & 5,88 & 2,59 \\
\hline $200.001-500.000$ & 22,00 & 4,00 & 3,03 \\
\hline 500.001 e mais & 15,80 & 8,29 & 4,67 \\
\hline Total & 14,75 & 6,50 & 3,56 \\
\hline \multicolumn{4}{|l|}{ Região Nordeste } \\
\hline $0-50.000$ & 7,62 & 6,43 & 3,59 \\
\hline $50.001-200.000$ & 7,19 & 5,84 & 3,31 \\
\hline $200.001-500.000$ & 21,00 & 4,90 & 3,57 \\
\hline 500.001 e mais & 9,84 & 5,91 & 3,91 \\
\hline Total & 9,68 & 5,85 & 3,73 \\
\hline \multicolumn{4}{|l|}{ Região Sudeste } \\
\hline $0-50.000$ & 4,28 & 3,69 & 2,73 \\
\hline $50.001-200.000$ & 5,60 & 4,24 & 2,98 \\
\hline $200.001-500.000$ & 4,66 & 4,25 & 3,00 \\
\hline 500.001 e mais & 8,26 & 5,52 & 3,38 \\
\hline Total & 6,88 & 4,94 & 3,18 \\
\hline \multicolumn{4}{|l|}{ Região Sul } \\
\hline $0-50.000$ & 8,56 & 3,96 & 2,66 \\
\hline $50.001-200.000$ & 5,85 & 3,63 & 2,61 \\
\hline $200.001-500.000$ & 9,88 & 4,14 & 2,70 \\
\hline 500.001 e mais & 8,39 & 6,04 & 3,35 \\
\hline Total & 7,97 & 4,56 & 2,87 \\
\hline \multicolumn{4}{|l|}{ Região Centro-Oeste } \\
\hline $0-50.000$ & 12,50 & 3,46 & 2,39 \\
\hline $50.001-200.000$ & - & 2,29 & 2,44 \\
\hline $200.001-500.000$ & 8,38 & 6,18 & 3,07 \\
\hline 500.001 e mais & 9,58 & 5,04 & 3,32 \\
\hline Total & 10,25 & 4,61 & 3,02 \\
\hline \multicolumn{4}{|l|}{ Brasil } \\
\hline $0-50.000$ & 5,48 & 4,08 & 2,77 \\
\hline $50.001-200.000$ & 5,89 & 4,13 & 2,88 \\
\hline $200.001-500.000$ & 5,26 & 4,31 & 2,98 \\
\hline 500.001 e mais & 8,45 & 5,58 & 3,44 \\
\hline Total & 7,23 & 4,96 & 3,17 \\
\hline
\end{tabular}

* Não foi possível calcular a razão de sexos, em virtude da ausência de casos de AIDS em mulheres no período analisado, no conjunto de municípios pertencentes a este estrato. 
Tabela 5

Distribuição (\%) dos casos notificados de AIDS, segundo grande região e categoria de exposição por período de tempo. Brasil, 1987-1996.

\begin{tabular}{|c|c|c|c|}
\hline \multirow[t]{2}{*}{ Categoria de exposição } & \multicolumn{3}{|c|}{ Período de tempo } \\
\hline & 1987-89 & 1990-92 & 1993-96 \\
\hline \multicolumn{4}{|l|}{ Região Norte } \\
\hline Homo/bi & 56,3 & 47,1 & 34,9 \\
\hline Hetero & 7,9 & 17,1 & 30,1 \\
\hline UDI & 0,8 & 10,2 & 8,4 \\
\hline Sangue & 4,8 & 3,6 & 3,9 \\
\hline Ignorada & 30,2 & 21,9 & 22,8 \\
\hline \multicolumn{4}{|l|}{ Região Nordeste } \\
\hline Homo/bi & 62,7 & 50,5 & 40,9 \\
\hline Hetero & 5,2 & 14,5 & 28,5 \\
\hline UDI & 10,3 & 11,5 & 8,4 \\
\hline Sangue & 5,2 & 3,5 & 2,9 \\
\hline Ignorada & 16,6 & 20,0 & 19,3 \\
\hline \multicolumn{4}{|l|}{ Região Sudeste } \\
\hline Homo/bi & 50,3 & 30,9 & 21,7 \\
\hline Hetero & 8,3 & 15,0 & 24,6 \\
\hline UDI & 19,5 & 33,2 & 25,8 \\
\hline Sangue & 5,8 & 3,4 & 2,4 \\
\hline Ignorada & 16,1 & 17,6 & 25,5 \\
\hline \multicolumn{4}{|l|}{ Região Sul } \\
\hline Homo/bi & 58,2 & 33,9 & 19,4 \\
\hline Hetero & 8,6 & 14,9 & 29,8 \\
\hline UDI & 14,3 & 34,3 & 30,7 \\
\hline Sangue & 4,4 & 2,3 & 1,6 \\
\hline Ignorada & 14,6 & 14,6 & 18,5 \\
\hline \multicolumn{4}{|l|}{ Região Centro-O este } \\
\hline Homo/bi & 58,8 & 32,9 & 19,2 \\
\hline Hetero & 8,4 & 14,9 & 27,3 \\
\hline UDI & 12,3 & 24,3 & 19,6 \\
\hline Sangue & 3,7 & 2,1 & 2,1 \\
\hline Ignorada & 16,8 & 25,8 & 31,9 \\
\hline \multicolumn{4}{|l|}{ Brasil } \\
\hline Homo/bi & 52,2 & 33,1 & 23,1 \\
\hline Hetero & 8,0 & 14,9 & 25,9 \\
\hline UDI & 18,0 & 30,9 & 24,4 \\
\hline Sangue & 5,6 & 3,2 & 2,3 \\
\hline Ignorada & 16,2 & 17,9 & 24,3 \\
\hline
\end{tabular}

análise é constituída exclusivamente por dados relativos aos indivíduos singulares (Mann \& Tarantola, 1996).

Da presente análise, foi possível constatar que a epidemia pelo HIV/ AIDS no Brasil experimentou modificações profundas no seu escopo: de marcadamente regional e basicamente restrita a determinados segmentos populacionais em seu início, passou a crescentemente nacional ao longo do período, trazendo novos desafios às políticas públicas e à ação da sociedade civil.

Ficou claro igualmente que a epidemia vem-se disseminando de forma mais lenta em anos recentes, segundo uma dinâmica que resulta, provavelmente, da combinação entre saturação de segmentos sob maior risco - ou seja, o relativo esgotamento do contingente de suscetíveis (Gupta et al., 1989) -, mudança comportamental espontânea de certos segmentos populacionais e impacto de diferentes iniciativas preventivas voltadas para distintos segmentos populacionais por iniciativa tanto de organizações governamentais como não-governamentais (Mattos, 1999).

Cabe destacar, no entanto, que esta relativa desaceleração da disseminação da epidemia não se dá de forma homogênea, seja do ponto de vista dos segmentos populacionais mais diretamente afetados, seja das diferentes regiões geográficas. A velocidade de expansão decresce basicamente entre os homens nas cidades de maior porte e na Região Sudeste, enquanto determinados segmentos populacionais como, por exemplo, os usuários de drogas injetáveis, continuam a ser desproporcional mente afetados pela epidemia.

Como foi possível observar pelos resultados deste estudo, a Região Sudeste ainda exerce papel de relevância por razões diversas: trata-se da região mais populosa e mais intensamente interligada pelas vias de comunicação (Barcellos \& Bastos, 1996); da região mais urbanizada e que conta com maior número de municípios de grande e médio porte (mais precocemente atingidos pela epidemia) e ainda da região onde a epidemia é mais antiga (MS, 1999). Por sua vez, esta região, onde o fenômeno de saturação de segmentos sob maior risco parece ser mais relevante e onde têm sido desenvolvidas com maior intensidade e abrangência ações preventivas, tende a entrar em fase de estabilidade, com taxas de crescimento em nítido declínio.

No período mais recente, é de destaque a participação crescente da Região Sul, não só pela freqüência de casos de AIDS registrados em UDI (Bastos et al., 1999), como também pelo aumento do número de casos decorrentes da 
transmissão heterossexual. Levando em conta não só a velocidade de expansão, como a sua magnitude relativa frente ao conjunto da epidemia nacional, constata-se que esta região merece atenção especial dos formuladores de políticas preventivas.

A clara disseminação da epidemia de AIDS entre os municípios pequenos na direção noroeste, partindo do litoral sul para as regiões Centro-Oeste e Norte, igual mente deve merecer consideração específica, procurando-se definir claramente os epicentros da epidemia com maior relevância em anos mais recentes e implementando-se diferentes estratégias de prevenção. Neste sentido, as áreas de exploração de minérios, como o ferro, a bauxita e a cassiterita, no Pará, onde são criados novos postos de trabaIho vinculados ao garimpo, acabam por tornarse focos de atração da população, em especial, de homens jovens sem as respetivas famílias (Becker, 1990), e devem ser objeto particular de investigação e medidas preventivas específicas.

Dadas as características históricas do povoamento brasileiro, com reflexos que persistem até nossos dias, fazendo com que as principais regiões metropolitanas estejam situadas no litoral ou lhe sejam contíguas, é possível falar em um processo de interiorização da epidemia, à medida que a malha municipal é afetada, de modo gradual, pelo processo de expansão da epidemia em curso. Ao longo do período não só maior número de municípios é atingido, como este processo abrange, de forma crescente, municípios de menor porte, via de regra, dispondo de menos recursos no âmbito da saúde e de recursos comunitários de modo geral.

Se não resta dúvida de que a epidemia de AIDS, como um todo, difundiu-se ao longo de todo o período a partir das principais metrópoles em direção a municípios de médio e, subseqüentemente, em direção àqueles de pequeno porte, em um processo que poderia ser comparado a uma disseminação hierarquicamente decrescente em direção ao conjunto da malha municipal, este processo não é homogêneo quanto ao grau de urbanização dos municípios nem no que se refere às diferentes categorias de exposição.

A disseminação é nitidamente seletiva no que diz respeito ao grau de urbanização, privilegiando os municípios predominantemente urbanos, que têm, em geral, as maiores densidades demográficas e estão sob interação mais intensa com as demais localidades, em decorrência da interligação por meio de estradas e outros meios de transporte, o que facilita o deslocamento da população, o movimento pendular da força-de-trabalho sazonal e o transporte
Tabela 6

Distribuição (\%) dos casos notificados de AIDS, segundo categoria populacional e categoria de exposição por período de tempo. Brasil, 1987-1996.

\begin{tabular}{|c|c|c|c|}
\hline \multirow{2}{*}{$\begin{array}{l}\text { Categoria populacional/ } \\
\text { Categoria de exposição }\end{array}$} & \multicolumn{3}{|c|}{ Período de tempo } \\
\hline & 1987-89 & 1990-92 & $1993-96$ \\
\hline \multicolumn{4}{|l|}{$0-50.000$} \\
\hline Homo/bi & 48,2 & 28,2 & 17,8 \\
\hline Hetero & 11,9 & 19,5 & 34,1 \\
\hline UDI & 17,9 & 28,6 & 22,9 \\
\hline Sangue & 7,7 & 5,3 & 3,2 \\
\hline Ignorada & 14,2 & 18,4 & 22,0 \\
\hline \multicolumn{4}{|l|}{$50.001-200.000$} \\
\hline Homo/bi & 44,9 & 23,5 & 16,7 \\
\hline Hetero & 9,0 & 16,6 & 29,7 \\
\hline UDI & 25,2 & 42,5 & 33,3 \\
\hline Sangue & 6,5 & 3,2 & 2,2 \\
\hline Ignorada & 14,4 & 14,2 & 18,1 \\
\hline \multicolumn{4}{|l|}{$200.001-500.000$} \\
\hline Homo/bi & 41,2 & 24,7 & 18,3 \\
\hline Hetero & 9,6 & 16,9 & 28,3 \\
\hline UDI & 30,7 & 40,8 & 31,8 \\
\hline Sangue & 6,1 & 2,8 & 2,1 \\
\hline Ignorada & 12,4 & 14,9 & 19,4 \\
\hline \multicolumn{4}{|l|}{500.001 e mais } \\
\hline Homo/bi & 56,3 & 38,4 & 28,0 \\
\hline Hetero & 7,3 & 13,5 & 22,4 \\
\hline UDI & 13,7 & 25,2 & 18,7 \\
\hline Sangue & 5,2 & 3,2 & 2,3 \\
\hline Ignorada & 17,6 & 19,7 & 28,6 \\
\hline
\end{tabular}

de cargas, com a concomitante movimentação do pessoal envolvido nestas atividades (Santos, 1993).

No tocante às categorias de exposição, a epidemia, em sua fase inicial, atingia principalmente a categoria dos homens que fazem sexo com outros homens e a dos hemofílicos e demais pessoas que receberam sangue e hemoderivados. Os usuários de drogas injetáveis, mais diretamente afetados em período subseqüente, desempenharam papel central no processo de expansão para municípios de porte médio e mesmo pequeno, a partir de uma disseminação inicial ao longo da faixa que conecta o Centro-Oeste ao interior paulista (Barcellos $\&$ Bastos, 1996) e, mais recentemente, no litoral sul do País (Bastos et al., 1999).

Atualmente, a transmissão heterossexual do HIV é o "motor" da dinâmica da epidemia, com expressão relevante em todas as regiões, 
Distribuição dos municípios segundo a predominância de população residente em área rural/urbana e o período quanto à notificação de casos de AIDS. Brasil.

predominantemente rurais

$1990-92$

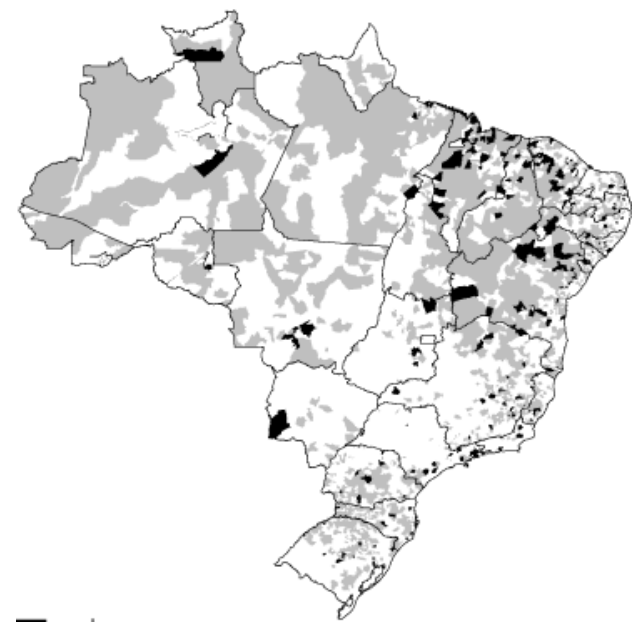

pelo menos um caso

nenhum caso

predominantemente urbano
1994-96
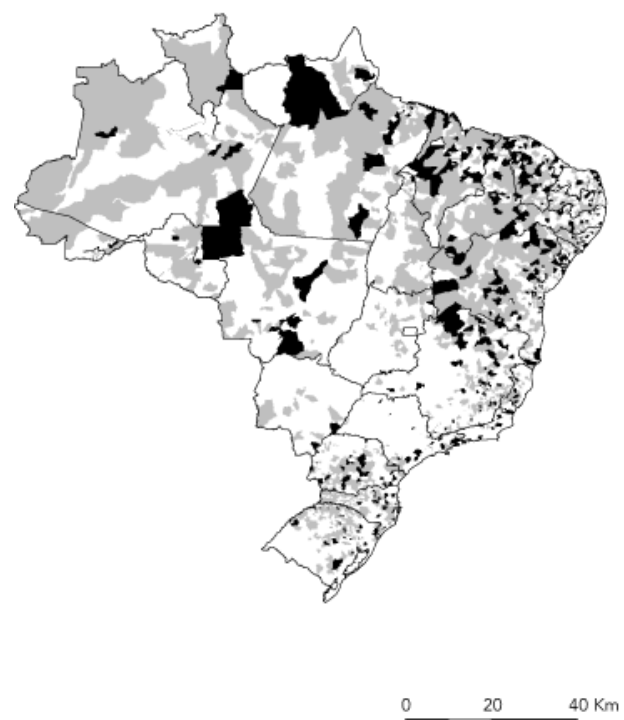

predominantemente urbanos

1990-92

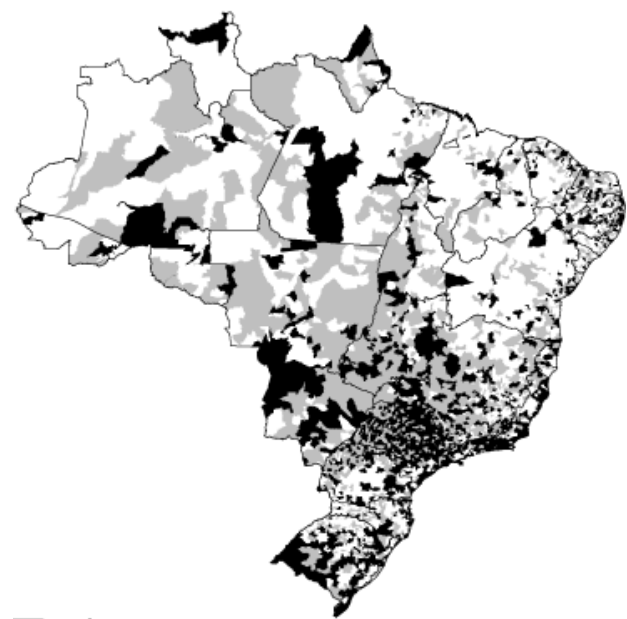

pelo menos um caso

nenhum caso

predominantemente rural
1994-96
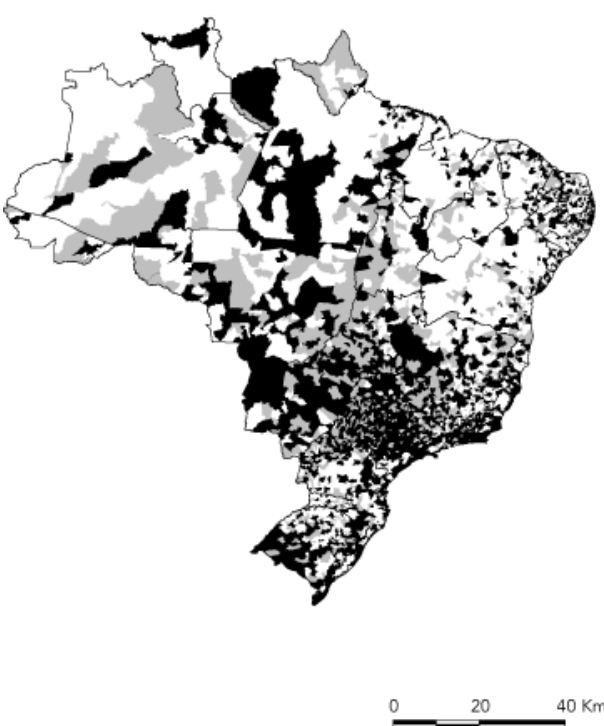
Figura 3

Distribuição dos municípios segundo a situação de concentração de pobreza e o período quanto à notificação de casos de AIDS. Brasil.

relativamente mais ricos

$1990-92$

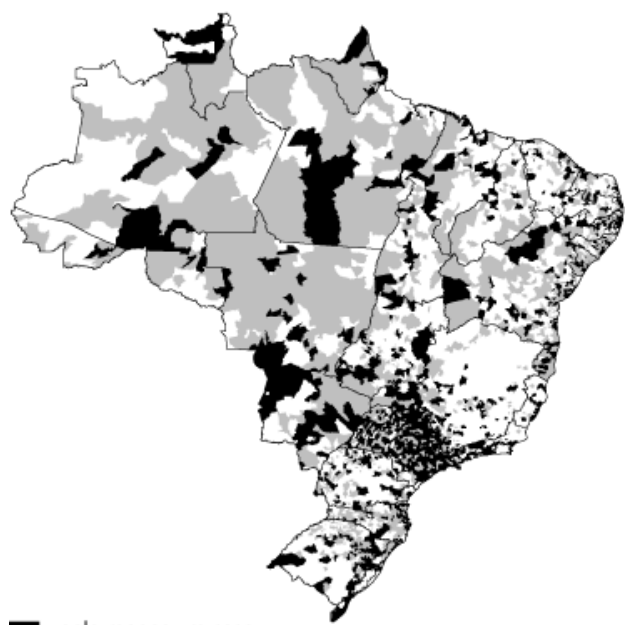

pelo menos um caso

nenhum caso

relativamente mais pobres
1994-96
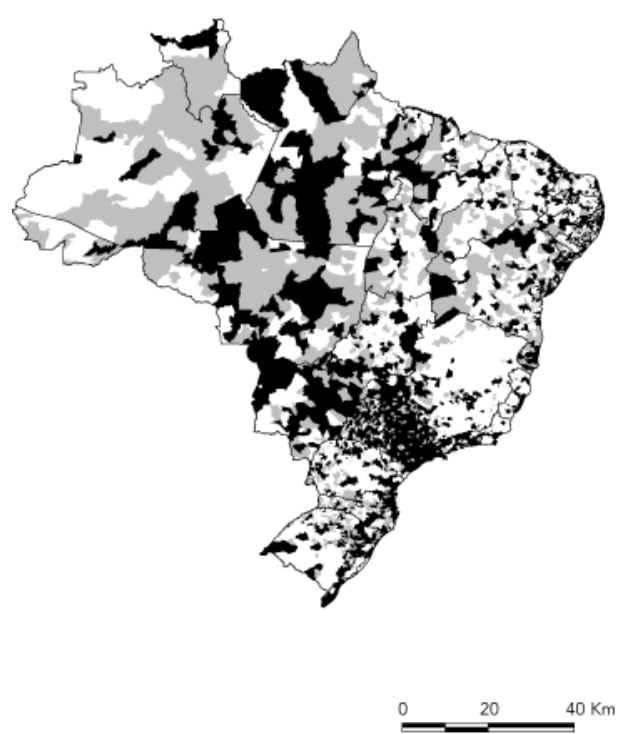

relativamente mais pobres

1990-92

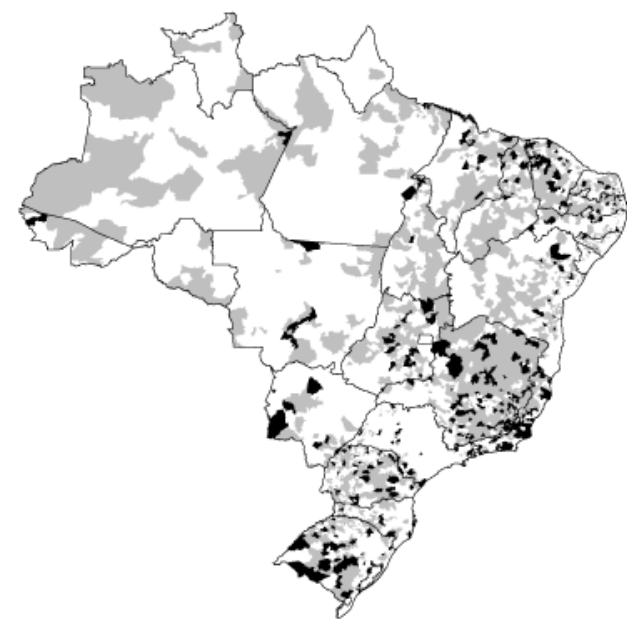

pelo menos um caso

nenhum caso

relativamente mais ricos
1994-96

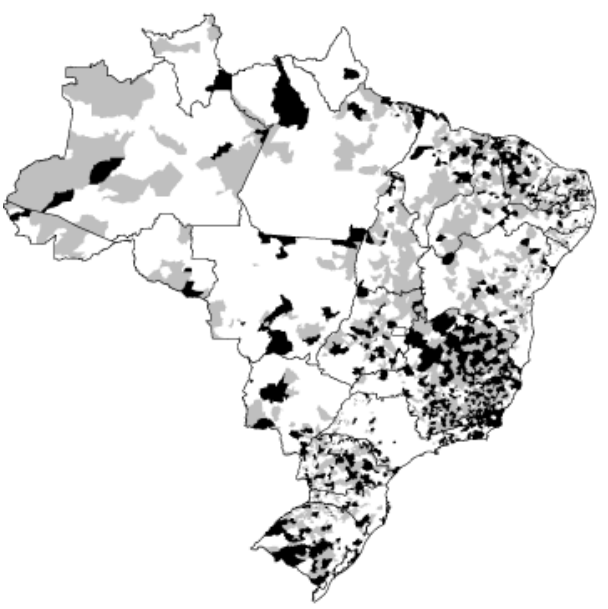

$20 \quad 40 \mathrm{Km}$ 
Percentual (\%) dos municípios com população menor ou igual a 50 mil habitantes com pelo menos um caso de AIDS notificado no período, segundo a situação urbano/rural e a concentração de pobreza por período de tempo. Brasil, 1990-92 e 1994-96.

\begin{tabular}{|c|c|c|}
\hline \multirow[t]{2}{*}{ Situação/concentração de pobreza } & \multicolumn{2}{|c|}{ Percentual (\%) de municípios } \\
\hline & 1990-92 & 1994-96 \\
\hline \multicolumn{3}{|l|}{ Predominantemente urbanos } \\
\hline Relativamente mais ricos & 37,1 & 54,8 \\
\hline Relativamente mais pobres & 21,3 & 39,7 \\
\hline Total & 30,3 & 48,3 \\
\hline \multicolumn{3}{|l|}{ Predominantemente rurais } \\
\hline Relativamente mais ricos & 8,2 & 19,2 \\
\hline Relativamente mais pobres & 9,7 & 19,9 \\
\hline Total & 9,1 & 19,6 \\
\hline \multicolumn{3}{|l|}{ Total } \\
\hline Relativamente mais ricos & 25,9 & 41,0 \\
\hline Relativamente mais pobres & 15,3 & 29,5 \\
\hline Total & 20,7 & 35,4 \\
\hline
\end{tabular}

contribuindo também, de modo decisivo, para o aumento de casos de AIDS entre as mulheres. Em nenhum outro momento de sua ampliação, a epidemia atingiu de forma tão abrangente o conjunto da malha municipal brasileira como agora, em que a principal via de transmissão se confunde com os hábitos sexuais da população dita geral, ou seja, dificultando a definição de regiões e segmentos específicos sob risco, e reivindicando uma grande abrangência das intervenções preventivas.

Em suma, após um período em que a concentração espacial se fez acompanhar de seletividade do processo de disseminação com relação às categorias de exposição, no início da década de 80, a epidemia pelo HIV/ AIDS passou a atingir, crescentemente, novos segmentos populacionais. Seguindo um padrão, grosso modo, bifásico de disseminação, descrito por Gupta et al. (1989), que combina um momento de rápida disseminação e saturação em segmentos específicos sob alto risco e um momento posterior de disseminação mais lenta, porém mais extensa - dado o maior contingente populacional afetado no momento subseqüente - , a epidemia brasileira parece atravessar hoje uma "segunda" etapa, através de sua expansão para amplo conjunto de pessoas com padrões comportamentais ditos de "baixo risco", segundo os indicadores tradicionais de avaliação da vulnerabilidade individual (ver ainda Barbosa et al., neste fascículo).
Parece avultar aí a questão da vulnerabilidade social, fazendo com que as pessoas com menores níveis de educação formal, inseridas em ocupações mal-remuneradas ou excluídas do mercado formal de trabalho (Grangeiro, 1994), com acesso restrito aos cuidados de saúde e a outras políticas de promoção social e comunitária se exponham cada vez mais à infecção pelo HIV. Este processo combinaria dimensões materiais (falta de recursos para adquirir preservativos ou seringas estéreis); variáveis no âmbito biomédico, como a maior prevalência de infecções sexualmente transmissíveis (facilitando a transmissão sexual do HIV) entre os mais pobres; e variáveis da ordem da subjetividade individual e micro-grupal, como desigualdades de gênero, conflito entre iniciativas de auto-proteção e outras demandas prementes com relação à alimentação ou moradia (Bastos \& Szwarcwald, neste fascículo).

Mais do que nunca, os profissionais de saúde, o governo e a sociedade civil se vêem às voltas com imenso desafio. 


\section{Agradecimentos}

Linha de trabalho financiada pelo Ministério da Saúde e pelo Conselho Nacional de Desenvolvimento Científico e Tecnológico - CNPq. Este trabalho foi financiado pela Coordenação de DST e AIDS do Ministério da Saúde.

\section{Referências}

ANDRADA-SERPA, M. J.; TOSSWILL, J.; SCHOR, D.; LINHARES, D.; DOBBIN, J. \& PEREIRA, M. S., 1989. Seroepidemiologic survey for antibodies to human retroviruses in human and non-human primates in Brazil. International Journal of Cancer, 44:389-393.

BARBOSA, M. T. S. \& STRU CHINER, C. J., 1997. Estimativas do número de casos de AIDS: Comparação de métodos que corrigem o atraso da notificação. In: A Epidemia de AIDS no Brasil: Situação eTendências (Ministério da Saúde, org.), pp. 1526, Brasília: Coordenação Nacional de DST eAIDS, Ministério da Saúde.

BARCELLOS, C. \& BASTOS, F. I., 1996. Redes sociais e difusão da AIDS no Brasil. Boletín dela Oficina Sanitaria Panamericana, 121:11-24.

BASTOS, F. I.; STRATHDEE, S. A.; DERRICO, M. \& PINA, F., 1999. Drug use and the spread of HIV/ AIDS in South America and the Caribbean. Drugs: Education, Prevention \& Policy, 6:29-50.

BASTOS, F. I.; TELLES, P. R.; CASTILHO, E. A. \& BARCELLOS, C., 1995. A epidemia de AIDS no Brasil. In: Os Muitos Brasis: Saúde e População na Década de 80 (M. C. S. Minayo, org.), São Paulo: Editora Hucitec/Rio de Janeiro: ABRASCO.

BECKER, B. K., 1990. Amazônia. São Paulo: Editora Ática.

CARVALHO, M. I.; CASTELO-BRANCO, L. R.; RABIB, J. G. A.; GALVÃO-CASTRO, B. \& PEREIRA, M. S., 1987. HIV antibodies in beggar blood donors in Rio de Janeiro. Memórias do Instituto Oswaldo Cruz, 82:587-588.

IBGE (Fundação Instituto Brasileiro de Geografia e Estatística), 1983. Censo Demográfico, 1980. Rio de Janeiro: IBGE.

IBGE (Fundação Instituto Brasileiro de Geografia e Estatística), 1993. Censo Demográfico, 1991. Rio de Janeiro: IBGE.

IBGE (Fundação Instituto Brasileiro de Geografia e Estatística), 1997. Contagem da População, 1996. Rio de Janeiro: IBGE.
FONSECA, M. G. P. \& CASTILHO, E. A, 1997. Os casos de AIDS entre usuários de drogas injetáveis. Brasil, 1980-1997. Boletim Epidemiológico - AIDS, $\mathrm{X}: 6-14$.

GRANGEIRO, A., 1994. O perfil sócio-econômico da AIDS no Brasil. In: A AIDS no Brasil (R. Parker, C. Bastos, J. Galvão \& S. Pedrosa, eds.), pp. 91-128, Rio de Janeiro: ABIA/UERJ/Editora Relume-Dumará.

GUPTA, S.; ANDERSON, R. M. \& MAY, R. M., 1989. Networks of sexual contacts: Implications for the pattern of spread of HIV. AIDS, 3:807-817.

MANN, J. \& TARANTOLA, D., 1996. AIDS in the World II. New York/Oxford: Oxford University Press.

MAPINFO, 1994. MapInfo Reference. Nova York: MapInfo Corporation.

MATTOS, R., 1999. Sobre os limites e as possibilidades dos estudos acerca dos impactos das políticas públicas relativas à epidemia de HIV/ AIDS: Algumas reflexões metodológicas feitas a partir do caso brasileiro. In: Saúde, Desenvolvimento e Política: Respostas frente à AIDS no Brasil (R. Parker, J. Galvão \& M. S. Bessa, eds.), pp. 29-90, São Paulo: Editora 34.

MS (Ministério da Saúde), 1999. Boletim EpidemioIógico - AIDS, XII, Semana Epidemiológica 09 a 21, março/maio.

PARKER, R., 1994. A Construção da Solidariedade. Rio de Janeiro: ABIA/UERJ/Editora Relume-Dumará.

PORTER, K.; JOHNSON, A. M.; PHILLIPS, A. N. \& DARBYSHIRE, J. H., 1999. The practical significance of potential biases in estimates of the AIDS incubation period distribution in the UK register of HIV seroconverters. AIDS, 13:1943-1951.

SANTOS, M., 1993. A Urbanização Brasileira. São Paulo: Editora Hucitec.

UNAIDS (The Joint United Nations Programme on HIV/AIDS), 1999. UNAIDS 3rd Meeting of the Latin America and Caribbean Epidemiological Network, Abstracts. Cuernavaca: UNAIDS. 